\title{
The cloud hovering over the virtual campus
}

\author{
Marc Alier, Enric Mayol, María José Casañ \\ Universidad Politécnica de Catalunya - BarcelonaTech \\ UPC Campus Nord, Omega S206 \\ Jordi Girona 1-3, 08034, Barcelona, Spain \\ (+34) 934137885
}

\begin{abstract}
The Virtual Campus has been around for about 20 years. It provides an online environment that mimics the processes and services of the physical campuses and classrooms. Its adoption is almost complete in countries where Internet access has become ubiquitous. For a time seemed like the innovation in education was happening in the Virtual Campus, but this is no more.

Personal Learning Environments, Life Long Learning, MOOCS, Open Educational Resources, Mobile Apps, Gamification, Social Networks, free Cloud based services ... al of the above and even more hint that not all the learning today is happening at school or in the Virtual Campus.
\end{abstract}

\section{Categories and Subject Descriptors}

K.3.1 [Computers and Education]: Computer Uses in Education - Collaborative learning, Computer-assisted instruction (CAI)

K.3.2 [Computers and Education]: Computer and Information Science Education - Accreditation, Curriculum

\section{General Terms}

Education, e-learning Software as a Service,

\section{Keywords}

e-learning, eLearning, lifelong learning, cloud computing, PLE' software as a service, mlearning, m-learning

\section{INTRODUCTION}

The Virtual Campus software (or Learning Management System LMS, Course Management System CMS, Virtual Learning Environment VLE) has been around for about 20 years. It provides an online environment that mimics the processes and services of the physical campuses and classrooms. Its adoption is almost complete in countries where Internet access has become ubiquitous.

For a time seemed like the innovation in education was happening in the LMS with introduction of peer grading systems, wikis or project based learning extensions. Leading the bottom up innovation in 2002 the Open Source software Moodle gained a huge chunk of the market with its teacher friendly approach being the course the central object from where everything goes and the teacher in control of it - with an easy extension development kit and a huge online community of developers and users with more than one million registered users by 2011 .

In the private market Blackboard became the number one vendor buying out almost any competitor out there. And thus we got a stable market with very few actors and with a clear winner in each market: Moodle in the Open Source space: and Blackboard among the vendors.

For a time looked like the LMS was enough. But just for a time. Soon became clear that LMS are not ready of the challenges just in the next corner. In this paper we introduce some challenges that

\author{
\{ludo, mayol, mjcasany\}@essi.upc.edu
}

among others could be discussed in the Track Software As A Service (SAAS) in learning processes, in the 2014 TEEM conference.

\section{CHALLENGES IN THE CLOUD}

\subsection{The social networks}

In the early 2000s the students where pleased to use the LMS as a tool for learning and communication. Lacking other means of online communication students participated fully in forums, wikis and other tools available inside the virtual campus. But when the students are already connected via cloud based tools like myspace, facebook, whatsup the teacher has little hope of getting the students to interact in the virtual class. The students already have communication channels in place.

Is the social network a menace to the interaction within the classroom or the virtual one? Or can it be turned into an asset? How?

\subsection{The Wide Wild Web}

Is the textbook obsolete? All the information and content proposed by the teacher has to compete with Exabytes of freely available information and content barely curated by Google's Pagerank algorithm. Youtube alone offers bilions of videos a huge percentage under the label educational or instructional. Notwithstanding the availability of quality educational content in MOOCs, Open Educational Resources (OERs') , Open Courseware, iTunesU etc.

\subsection{Mobile LMS}

Market penetration of smartphones is almost complete in developed countries. But our huge LMS are not ready for mobile, short of doing some tweaks to its layout to be mobile responsive. The design of most current LMS has been thought with a big screen and a mouse in mind. It will take a lot of thinking and changes to make current LMS mobile ready. Meanwhile the new design needs for Mobile and MOOCS open a door for new, more interoperable and lightweight LMS. Are we facing a refragmentation of the market?

\subsection{Long life learners}

Long Life Learning is the new paradigm of understanding education. The information society is evolving very fast, job descriptions change with the accelerating change of technologies and the pace in which society is integrating the. A student today needs to know that what she will learn while at school and college will not be enough and that she will need to continue to learn during the rest of her life to stay productive.

A long life learner will need at some point to get in control of her learning. She will need to track all the learning she is getting from formal, non formal and informal learning experiences, being in 
control of her Personal Learning Environment formalized in a Personal Learning Portfolio. What information is she going to get from the current LMS to feed her portfolio?

\section{THE LMS IN THE CLOUD}

The current LMS, the ones in use worldwide - Moodle, Blackboard, Sakai, etc. Where envisioned and designed in the early 2000's before the Web 2.0 eruption and developed in the prevalent architectures and paradigms.

Today we live in an Internet of Cloud computing, mobile devices and highly interoperable services and if we where to design a LMS from scratch we would take a different approach.

But when a big institution has integrated a LMS into its enterprise systems, trained all its personnel to use it and taken all those little decisions that make an enterprise software work in an organization is not so easy to replace it.

So the challenge is how we integrate our current LMS educational institutions with the new Internet that keeps growing around them? Lets talk about it in Salamanca 